\title{
IMPLEMENTACIJA JEDINSTVENOG EVROPSKOG BROJA 112 ZA HITNE SLUČAJEVE U REPUBLICI SRBIJI - PREDNOSTI I NEDOSTACI
}

\author{
Miloš Milenkovići ${ }^{*}$, \\ Dalibor Kekić2, \\ Darko Glavaš ${ }^{3}$
}

\author{
${ }^{1}$ Ministarstvo unutrašnjih poslova - \\ Beograd, Srbija \\ ${ }^{2}$ Kriminalističko - policijska akademija, \\ Beograd, Srbija \\ ${ }^{3}$ Grad Beograd - Sekretarijat za poslove \\ odbrane, vanrednih situacija, komunikacije i \\ koordinaciju odnosa sa građanima, \\ Belgrade, Serbia
}

\begin{abstract}
Rezime:
U slučaju elementarnih nepogoda i tehničko - tehnoloških nesreća, koje izazivaju ozbiljne posledice u smislu ljudskih žrtava i materijalne štete, jedan od bitnih kriterijuma za pružanje efikasnog i efektivnog odgovora jeste i brzina reagovanja. Takođe, u slučaju značajnijih opasnosti po ljude, materijalna i kulturna dobra, očekuje se angažovanje ljudskih i materijalnih resursa koji pripadaju različitim službama u okviru sistema bezbednosti. Na primer, u slučaju da se dogodi saobraćajna nesreća sa težim posledicama, potrebno je angažovati pripadnike policijskih snaga, vatrogasno - spasilačkih jedinica, kao i službe hitne medicinske pomoći. Trenutno postoje različiti modeli pozivanja hitnih službi u slučaju potrebe. Međutim, na tlu evropskog kontinenta u velikoj meri rasprostranjena je upotreba jedinstvenog evropskog broja 112 za hitne slučajeve. Time se u tehničkom pogledu objedinjavaju sve nadležne službe i dobija se na brzini reagovanja. Većina evropskih zemalja prihvatila je ovaj broj kao zvaničan i u okviru sopstvene teritorije. Sa druge strane, u Republici Srbiji se i dalje koristi model razdvojenih telefonskih brojeva koji se koriste u slučaju potrebe za pozivanjem hitnih službi. Postoje incijative da se implementira jedinstveni evropski broj $112 \mathrm{u}$ narednom periodu. Međutim, i dalje su aktuelna ograničenja u smislu realizacije ovog složenog procesa. Pored niza prednosti koje donosi tehnička realizacija ovog broja, pojavljuju se i nedostaci, kao i ograničenja u pogledu informaciono - tehničke kompatibilnosti. Postoje i lokalni primeri nastojanja da se objedine podaci i informacije o radi i angažovanju hitnih službi, kao što je slučaj sa službom „Beokom servis” u okviru gradske uprave Grada Beograda.
\end{abstract}

Ključne reči:

hitne službe, evropski broj 112 za hitne slučaje, prednosti i nedostaci, „Beokom servis“, Grad Beograd.

\section{UVOD}

U slučaju kada dođe do vanrednih događaja ili situacija koji iziskuju združeni odgovor hitnih službi, odnosno policije, hitne medicinske pomoći i vatrogasno - spasilačkih jedinica, očekuje se pružanje odgovora u najkraćem mogućem roku. Razlog za to je činjenica da u slučaju angažovanja svih prethodno navedenih hitnih službi očekivano je da su ugroženi ljudski životi. U celom procesu pružanja odgovora kada dođe do potrebe za složenim intervencijama, možda jedan od ključnih segmenata je i alaramiranje, odnosno upućivanje poziva nadležnim službama
Odgovorno lice:

Miloš Milenković

e-pošta:

milos10jul@gmail.com 
o potrebi njihovog angažovanja. Naime, ranija svetska i evropska praksa poznavala je nekoliko brojeva koji su korišćeni u slučaju potrebe za pozivanjem hitnih službi. Takođe, telefonski brojevi za pozivanje su se razlikovali od države do države. Pored vremenskog nedostatka koji podrazumeva da se više telefonskih brojeva poziva da bi se sve relevantne službe angažovale, javljali su se problemi i prilikom boravka ili transporta stranih državljana u nedomicilnim zemljama. Na primer, u situacijama kada se strani državljanin nađe u opasnosti dolazilo je do poteškoća prilikom pozivanja hitnih službi iz razloga nejasnoća i nepoznavanja tehničkih detalja koji se odnose na način alarmiranja u slučaju potrebe. Prepoznavši potrebu da se uspostavi jedinstveni broj koji bi se koristio za pozivanje svih hitnih službi, Evropska unija, odnosno Savet Evropske unije, usvojio je Direktivu 91/396/EEC od 29. juna 1991. godine koja predstavlja međunarodni pravni akt na osnovu koga se uvodi jedinstveni broj za hitne slučajeve 112 [1]. Nakon ove odluke većina evropskih država pristupila je uvođenju jedinstvenog broja koji se koristi u slučaju pozivanja hitnih službi. Za ovaj proces neophodna su značajna sredstva, odnosno informaciono - komunikaciona oprema, sredstva radio i telekomunikacijske veze, kao i kadrovska osposobljenost. Na teritoriji Republike Srbije u upotrebi je i dalje nekoliko telefonskih brojeva koji se koriste za alarmiranje hitnih službi u slučaju potrebe, Postoje namere o implementiranju jedinstvenog evropskog broja za hitne slučajeve 112 , ali su evidentni nedostaci i prepreke u tehničkom I drugom pogledu kako bi se ovaj proces finalizovao.

\section{AKTUELNO STANJE NAČINA POZIVANJA HITNIH SLUŽBI U REPUBLICI SRBIJI}

Trenutno u Republici Srbiji aktuelno je nekoliko telefonskih brojeva koji se pozivaju u slučaju potrebe za hitnim službama, odnosno vatrogasce - spasioce, policiju i službu hitne medicinske pomoći. Na telefonski broj 193 pozivaju se vatrogasno - spasilačke jedinice, na telefonski broj 192 policijske snage, dok se na broj 194 poziva služba hitne medicinske pomoći. Takođe, trenutno je i dalje validan i broj 1985 kojim se aktivira Operativni centar, republički ili teritorijalno nadležni, i koji organizaciono pripada Sektoru za vanredne situacije Ministarstva unutrašnjih poslova Republike Srbije, i koji bi trebalo da predstavlja preteču budućeg centra 112. Kao što se može zaključiti, koristi se nekoliko različitih brojeva. Tehnički posmatrano, u praksi se moraju sve službe aktivirati putem različitih telefonskih brojeva.
To podrazumeva, da građani Republike Srbije koji se nalaze u opasnosti, i kojima je potrebna pomoć svih nabrojanih hitnih službi, moraju koristiti tri različita telefonska broja kako bi alarmirali sve nadležne hitne službe. Na taj način, gubi se vreme, koje je u slučaju opasnosti i više nego dragoceno, i minuti mogu odlučivati da li će neko koje u opasnosti preživeti. Sa druge strane, postavlja se i pitanje raspoloživosti i razmene informacija koje su dostupne hitnim službama. Razdvojenošću pozivanja, kao i usled dislociranosti operativnih centara i operatera svih nabrojanih službi, dolazi i do poteškoća kada je potrebno izvršiti analizu trenutne situacije, uraditi procenu, odnosno angažovati dovoljan broj operativnih snaga. Kada dolazi do angažovanja svih hitnih službi, zajednička procena trenutne situacije je izuzetno korisno sredstvo koje pomaže da se donesu adekvatne odluke, doprinese brzini reagovanja, kao i optimizuje broj ljudi i materijalno - tehničkih sredstava koji se angažuju. Treba ukazati da svaka od hitnih službi poseduje sopstveni operativni centar koji funkcioniše po principu 24-časovnog vremena po principu smenskog rada. U okviru operativnih, odnosno komandno - operativnih centara, rade operativci koji su prethodno prošli obuke za rad. Takođe, u svakoj od smena u centru je prisutan i rukovodilac smene, odnosno centra, koji bez obzira na formalno - pravni naziv radnog mesta, donosi neophodne odluke u skladu sa primljenim i obrađenim zahtevom za pomoć. Na primer, u slučaju da dođe do požara, građani koji su u opasnosti, odnosno primete požar, pozivaju telefonski broj 193. Prijem poziva, odnosno dojave, vrši teritorijalno nadležni komandno - operativni centar vatrogasno - spasilačke službe. Rukovodstvo, koje je trenutno prisutno u centru, donosi odluku o angažovanju operativnih snaga vatrogasno spasilačke službe i upućuje ih ka ugroženoj lokaciji. Do problema dolazi kada je prilikom operativnog odgovora potrebno i angažovanje drugih hitnih službi. Dešava se da ih građani ne alarmiraju, pa informacija do njih stiže tek po pristizanju, u slučaju požara, vatrogasaca - spasilaca na predmetnu lokaciju, što u nekim slučajevima može biti kasno.

Međutim, u skladu sa uočenim informaciono - tehničkim nedostacima trenutnog načina pozivanja hitnih službi, kao i procesom pristupanja Republike Srbije Evropskoj uniji, prepoznata je potreba implementacije jedinstvenog evropskog broja 112 za hitne slučajeve. Jedan od zakonskih akata koji prepoznaje formiranje službe 112 je i Zakon o vanrednim situacijama. U skladu sa ovim zakonom Služba 112 kao subjekat sistema osmatranja, ranog upozoravanja, obaveštavanja i uzbunjivanja obavlja sledeće zadatke: 
- primanje poziva za pomoć;

- rano upozoravanje, obaveštavanje i uzbunjivanje stanovništva, nadležnih organa, privrednih društava i drugih pravnih lica u zoni ugroženosti, kao i snaga zaštite i spasavanja;

- obezbeđenje jedinstvenog komunikaciono-informacionog sistema;

- obezbeđenje funkcionalne integracije službi od interesa za zaštitu i spasavanje i upravljanje vanrednim situacijama;

- obezbeđuje međunarodnu razmenu podataka u oblasti zaštite i spasavanja od posledica elementarnih nepogoda i drugih nesreća [2].

Takođe, u skladu sa istim zakonom Službu 112 čine Nacionalni centar 112, operativni centri 112, osmatračke stanice i sistem javnog uzbunjivanja, odnosno Nacionalni centar 112 i operativni centri 112, u skladu sa propisanom procedurom prikupljaju, analiziraju, prate i obaveštavaju nadležne organe i institucije o svim vrstama informacija iz oblasti vanrednih situacija. Nacionalni centar 112 obavlja međunarodne komunikacionoinformativne poslove iz oblasti zaštite od elementarnih nepogoda i drugih nesreća. Operativni centri 112 rade kao jedinstveni komunikaciono-informativni centar [2]. Međutim, u praksi oblik centra 112, koji zakon prepoznaje, funkcioniše, ali samo u domenu reagovanja na elementarne nepogode i tehničko - tehnološke nesreće. Pored toga, ako bi građani u slučaju potrebe pozvali broj 112 , poziv bi bio preusmeren na teritorijalno nadležnu policijsku upravu. Kao zaključak trenutnog stanja može se izvesti da se u Republici Srbiji i dalje koristi razdvojeni informacioni i telekomunikacioni način alarmiranja hitnih službi, odnosno da je početnoj fazi implementacija jedinstvenog evropskog broja 112 za hitne slučajeve, ali ne u svom izvornom obliku, odnosno onako kako predviđa regulative Evropske unije.

\section{PRIMENA JEDINSTVENOG EVROPSKOG BROJA 112 ZA HITNE SLUČAJEVE U EVROPSKIM DRŽAVAMA}

Trenutno, veliki broj država na tlu evropskog kontinenta, instalirao je i stavio u potpuno funkcionalno stanje jedinstveni evropski broj 112 za hitne slučajeve.

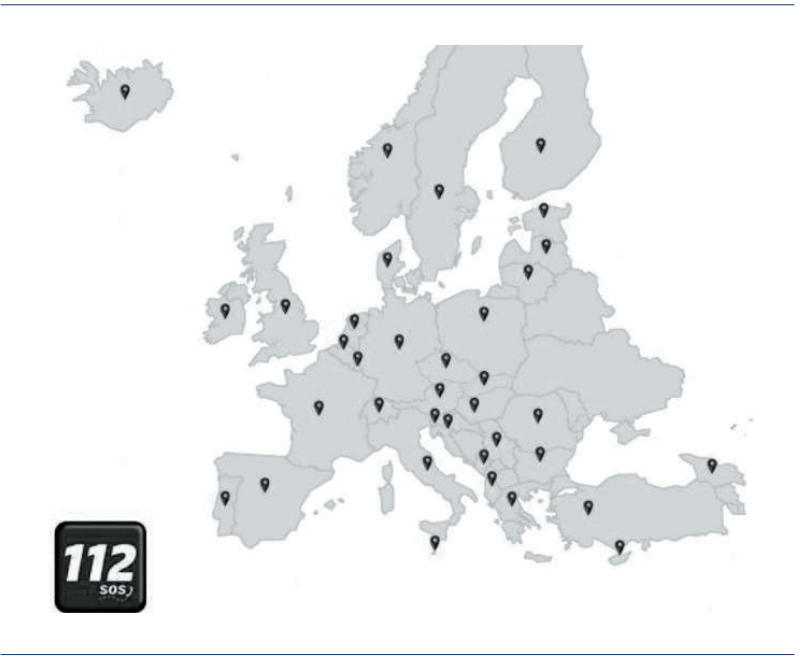

Slika 1. Mapa Evrope sa označenim državama u kojima je implementiran broj 112 [3]

$\mathrm{Na}$ osnovu prikazane mape, uočava se da je većina država implementirala ovaj broj, tačnije njih 36. Na listi se nalazi i Republika Srbija, međutim kako je i naznačeno u prethodnom poglavlju implementacija broja 112 nije u potpunosti realizovana.

Pored rasprostranjenosti upotrebe broja 112 na tlu evropskog kontinenta, postoje različiti informatičko komunikacioni i telekomunikacioni modeli implementacije. U skladu sa time Evropska asocijacija za pozivni broj za hitne slučajeve (EENA - European Emergency Number Association) tokom niza godina svog postojanja definisala je pet različitih modela koji su trenutno u upotrebi. Prema prvom modelu, operater pripada jednoj od hitnih službi. Ovakva rešenja su u upotrebi u Austriji, Nemačkoj, Francuskoj. Često predstavljaju nasleđe iz starijih vremena i stepenicu ka promeni sistema. Loša strana ovog modela je što širom zemlje mogu biti u upotrebi veoma različite tehnologije [4]. Prema drugom dostupnom modelu pozivi preko telefonskog broja 112 se filtriraju kroz centralnu tačku za prijem i onda prosleđuju do regionalnog centra neke od hitnih službi. Ovakva rešenja funkcionišu u Velikoj Britaniji i Holandiji. Prednost ovakvog modela je što se može ostvariti veća centralizacija službi za prijem poziva, a samim tim i uštede da bi se ostvarila potrebna funkcionalnost (na primer angažovanje prevodilaca za strane jezike i drugo) [4]. Treći model koji preporučuje EENA predlaže formiranje jedinstvenog operativnog centra tako da su sve hitne službe koncentrisane na jednoj lokaciji na regionalnom nivou. Jedna od službi je obično zadužena za primanje poziva. Ovaj model funkcioniše vrlo dobro u nekim evropskim gradovima kao što su Madrid u Španiji ili Ostrava u Češkoj Republici. Loša strana ovakvog modela može biti pitanje nadležnosti nad složenijim 
intervencijama [4]. Prema četvrtom modelu naglasak se stavlja na civilnu službu operatera i dispečera. Visokoobučeni civili (agencija) prihvataju pozive upućene na broj 112 i dispečuju jedinice potrebnih službi. Ovakav model je u upotrebi u Švedskoj, a zahteva visoku obučenost kadrova i snažnu tehničku podršku. Može se pojaviti surevnjivost između profesionalnih hitnih službi i civila koji im de facto izdaju naloge [4]. I peti, možda i najsavremeniji model, podrazumeva tačke prijema poziva upućenih na broj $112 \mathrm{su}$, uz upotrebu iste tehnologije, međusobno povezane u jedinstvenu mrežu. Poziv iz regiona $\mathrm{X}$ može biti prihvaćen i obrađen i u regionu Y. Ovo je vrlo efikasan model pošto svi PSAPi koriste istu tehnologiju i softver. Snažna tehnološka podrška je bitna s obzirom na to da svaki centar služi kao rezerva ostalima. Moguće je koristiti jedinstveni resurs sa prevodiocima za sve centre. Model je decentralizovan, pa je samim tim i lakši za primenu, ali zahteva jako centralno upravljanje s obzirom na zahtev za isti kvalitet usluge u svakom centru. Ovakav model funkcioniše u Češkoj Republici [4].

Može se zaključiti da se različita rešenja koriste, odnosno da svaki od njih sa sobom nosi određene prednosti i nedostatke. Svaka od država konstantno radi na unapređenju sistema i upotrebe jedinstvenog evropskog broja 112 za hitne slučajeve. Postoje slučajevi kada se započne sa upotrebom jednog modela, da bi se kasnije u cilju optimizacije i racionalizacije prešlo na upotrebu drugog modela. Pored toga, dosta se radi i na unapređenju dodatnih aplikacija koje pomažu građanima da što pre alarmiraju hitne službe u slučaju potrebe. Velika pažnja se posvećuje upotrebi geografskog informacionog sistema, odnosno GIS-a. Softver kao što je GIS, prevashodno je namenjen upotrebi od strane operatera kako bi što bolje locirali mesto opasnosti, kao i dostupnost najbližih operativnih snaga. Sa druge strane, sve više se radi na razvoju različitih aplikacija za uređaje mobilne telefonije kako bi građani mogli da u što kraćem roku preko broja 112 upute zahtev za pomoć. To su nove generacije upotrebe i primene broja 112. Nova tehnološka rešenja podrazumevaju da građani mogu da upute i SMS poruku operativnim centrima, da se može pratiti tonalitet glasa i time uočiti stepen opasnosti, odnosno da se automatski locira mesto opasnosti na osnovu upućenog poziva preko broja 112. Međutim, najveći izazov predstavlja što veća dostupnost broja 112 osobama sa invaliditetom. Naime, u skladu sa evropskim i svetskim tekovinama nastojanja su da se osobama sa invaliditetom omoguće što bolji uslovi za život. Kao i svi drugi, i oni se mogu naći u opasnosti. Ipak, pružanje pomoći tim osobama predstavlja znatno kompleksnije aktivnosti, a isto tako i njima je u slučaju opasnosti otežano da alarmiraju hitne službe. Neki od rešenja su da u operativnim centrima 112 budu uvek dostupne osobe koje poznaju način komunikacije osoba sa različitim invaliditetima i koji su obučeni da od njih prikupe sve neophodne informacije.

\section{IMPLEMENTACIJA JEDINSTVENOG EVROPSKOG BROJA 112 ZA HITNE SLUČAJEVE U REPUBLICI SRBIJI}

U radu je već ukazano da se u Republici Srbiji krenulo sa implementacijom broja 112. Trenutno se pozivom na broj 112 dobija komandno - operativni centar teritorijalno nadležne policijske uprave, u skladu sa lokacijom odakle je upućen poziv. U daljem toku, komandno - operativni centar alarmira nadležne službe koje su potrebne prilikom pružanja odgovora na opasnost koja proizilazi iz telefonskog poziva i zahteva za pomoć.

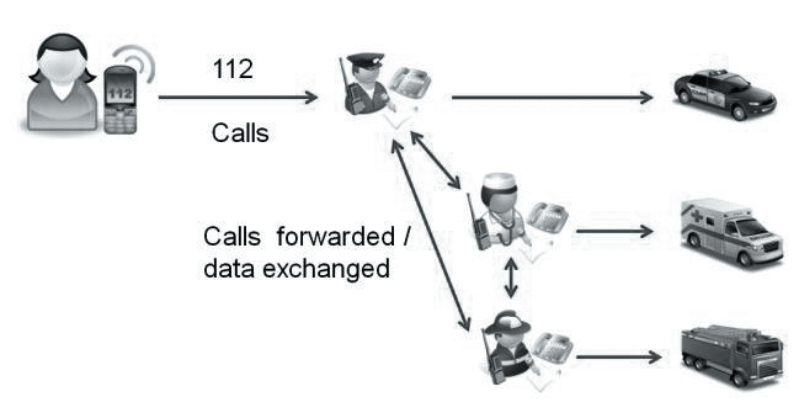

Slika 2. Nacrt izveštaja Ministarstva unutrašnjih poslova Republike Srbije [5]

Međutim, stručna i druga javnost stalno dovodi u pitanje da li je postojeći model adekvatan, odnosno da li treba menjati način informaciono - komunikacione i tehničke realizacije pozivanja službi u čijoj je odgovornosti pružanje hitnog odgovora u slučaju potrebe građana prvenstveno sa bezbednosnog aspekta. Bez obzira na prisutnost broja 112, u praksi se ovaj telefonski broj jako retko koristi. Naime, građani i dalje koriste telefonske brojeve 192, 193 i 194, u slučaju opasnosti.

$\mathrm{Na}$ osnovu tehničkih rešenja implementacije jedinstvenog evropskog broja 112 za hitne slučajeve, predlog je da se u Republici Srbiji zameni postojeće rešenje. Nekoliko nedostataka se vezuje za trenutno uspostavljeno rešenje funkcionisanja sistema 112. Prvi nedostatak koji je uočljiv je to što se od operativca u teritorijalno nadležnoj upravi očekuje da preuzme svu odgovornost za angažovanje hitnih službi. Toj osobi ne predstavlja problem kada se radi o potrebi angažovanja policijskih 
snaga, pošto je tada reč o njemu srodnoj oblasti. Do problema dolazi kada građani Republike Srbije koriste broj 112, a radi se o opasnostima gde je potrebno angažovanje vatrogasaca - spasilaca odnosno službe hitne medicinske pomoći. Na primer, može doći do izlivanja opasnih materija. Teško je očekivati da će policijski službenik koji primi poziv za pomoć preko broja 112 uspeti da prepozna sve potrebe koje se moraju zadovoljiti tokom intervencije. Dalje, sa aspekta informaciono - komunikacionih i telekomunikacionih sredstava, u modernim centrima 112 od operativaca se očekuje da koriste savremena tehničko - tehnološka rešenja. Policijski komandno - operativni centri nisu u dovoljnoj meri opremljeni odgovarajućom opremom putem koje se može pratiti i razmenjivati informacije sa različitim subjektima, po pitanju vremenske prognoze, stanja na putevima, bezbednosne situacije u naseljenim mestima. U većim gradovima Srbije, poput Beograda, Novog Sada, Kragujevca ili Niša postoje operativni centri policijskih uprava opremljeni savremenom opremom, poput računara sa softverskim rešenjima, odnosno video nadzora. Međutim, ostatak centara raspolaže sa jako skromnom opremom. Slična je situacija i sa operativnim centrima drugih službi, tačnije vatrogasno - spasilačkih jedinica i službe hitne - medicinske pomoći. Još jedan nedostatak koji je uočljiv jeste da građani Evrope koji se nalaze na privremenom boravku u Srbiji u većini slučajeve, a ukoliko se nađu u opasnosti, koristiće telefonski broj 112. Međutim, mali je broj operativaca u policijskim komandno - operativnim centrima koji bi mogli da snađu u situaciji da vrše prijem poziva koji se ostvaruje na engleskom ili nekom drugom stranom jeziku.

Postavlja se pitanje koji bi model bio najadekvatniji prilikom potpune implementacije jedinstvenog evropskog broja 112 za hitne slučajeve u Republici Srbiji. Sa aspekta višekriterijumskog odlučivanja možda bi najbolje rešenje bila kombinacija više modela. Kao osnova može se koristiti model koji se primenjuje u Velikoj Britaniji i Holandiji. Preporuka je da se formiraju četiri glavna operativna centra 112, u gradovima Beogradu, Novom Sadu, Kragujevcu i Nišu. Oni bi imali teritorijalno - podeljenu odgovornost za prijem poziva preko broja 112. Zahteve za angažovanjem operativnih snaga usmeravali bi ka teritorijalno najbližim jedinicama policije, vatrogasaca - spasilaca i službe hitne medicinske pomoći. Na ovaj način bi se ostvarile značajne uštede resursa. Po pitanju ljudi sa znanjem stranih jezika oni bi bili smešteni samo u glavnim operativnim centrima 112 i na taj način bi vršili prijem prvih poziva i dalju komunikaciju sa ugroženim stranim državljanima.
Dalje, slična je situacije i po pitanju komunikacije osoba sa invaliditetom. Takođe, u svakoj od smena u četiri glavna operativna centra nalazila bi se osoba obučena za komunikaciju sa osobama sa različitim tipovima invaliditeta. Još jedna od prednosti, tačnije ušteda koja bi se ostvarila, je potreba za savremenim informaciono - komunikacionim i telekomunikacionim sredstvima. Očekuje se upotreba savremenih softverskih rešenja koja omogućavaju i korišćenje satelitskih snimaka, automatsku procenu nastale situacije, dostupnost informacija o teritorijalno raspoloživim operativnim resursima. Pored primene ovog modela, predlaže se i kombinacija sa modelom koji podrazumeva međusobnu povezanost svih operativnih centara 112. Centri 112 u Beogradu, Novom Sadu, Kragujevcu i Nišu bili bi konstantno povezani informacioni - komunikacionim i telekomunikacionim sredstvima, pa bi jedan drugom predstavljali rezervne opcije. Na primer, ukoliko dođe do tehničke nemogućnosti prijema poziva u Novom Sadu, poziv bi automatski bi preusmeren ka centru u Beogradu, gde bi se vršila obrada i dalji odgovor. Pored niza prednosti, ovakav koncept ima i nekih nedostataka. Jedan od njih, je široka teritorijalna odgovornost koja bi se nametnula centrima. Naime, jedan od četiri centra pokrivao bi veći deo teritorije Republike Srbije. Postavlja se pitanje, koliko operater u Novom Sadu poznaje celu teritoriju Autonomne Pokrajine Vojvodine, koju bi pokrivao centar 112 u Novom Sadu.

Kao primer dobre prakse i rada na unapređenju komunikacije u slučaju angažovanja hitnih službi može se navesti Grad Beograd. Naime, Grad Beograd, kao glavni grad Republike Srbije i na čijoj teritoriji živi i boravi veliki broj ljudi, dnevno se suočava sa velikim brojem događaja kada se očekuje istovremeno angažovanje hitnih službi. Grad Beograd prepoznao je značaj formiranja centra koji bi bio centralna tačka sublimiranja poziva, prikupljanja podataka i angažovanja neophodnih službi, ali prevashodno delova komunalnog sistema. Sekretarijat za poslove odbrane, vanrednih situacija, komunikacije i koordinacije odnosa sa građanima, koji je nadležan za komunikaciju sa građanima, konstantno radi na unapređenju svog rada [6]. Osnivanjem „Beokom servis" znatno se ubrzalo pružanje odgovora kada je u pitanju angažovanje javnih komunalanih preduzeća čiji je osnivač Grad Beograd. Takođe, upotrebom različitih aplikacija, koje su dostupne građanima, kao i informaciono - komunikacionih sredstava, postiže se veći stepen efikasnosti u pružanju pomoći građanima. Na ovaj način ostvarena je i bolja komunikacija sa policijskom organizacijom, vatrogasno-spasilačkim jedinicama i službom 
hitne - medicinske pomoći. I dalje se radi na unapređenju rada ove gradske službe razvojem novih aplikacija i softverskih rešenja. Međutim, ovde se ne radi o upotrebi jedinstvenog evropskog broja 112 za hitne slučajeve u svom izvornom obliku, ali predstavlja dobru osnovu za budući centar 112 .

\section{ZAKLJUČAK}

Analize pokazuju da se u narednom periodu očekuje sve veći broj intervencija u kojima se očekuje angažovanje svih hitnih službi i združeni odgovor. Analize su rađene na globalnom nivou, ali statistika ukazuje da je slična situacija i sa teritorijom Republike Srbije. Iz tog razloga neophodna je što bolja komunikacija i bliža saradnja između policijskih snaga, vatrogasno - spasilačkih jedinica i službe hitne medicinske pomoći u prvom redu, kao i drugih relevantnih institucija u slučaju potrebe.

Evropska unija prepoznala je potrebu za unificiranjem i jedinstvenim načinom pozivanja hitnih službi kroz upotrebu jedinstvenog broja 112 za hitne slučajeve. Naime, trenutno je vrlo mali broj evropskih država koje ne koriste ovaj broj. Pored evropskog kontinenta, u Sjedinjenim Američkim Državama po istoj osnovi se koristi telefonski broj 911.

Republika Srbija započela je implementaciju broja 112. Trenutno, u slučaju opasnosti pozivom na broj 112 dobija se teritorijalno nadležna policijska uprava koja dalje preusmerava zahtev. Međutim, građani Srbije su ne u velikoj meri upoznati sa mogućnošću upotrebe ovog broja, pa se i dalje radi po staroj metodici, odnosno korišćenjem brojeva 192, 193 i 194.
Potrebno je u narednom periodu raditi na razvoju upotrebe broja 112. To podrazumeva složen proces prilagođavanja novom načinu komunikacije i saradnje hitnih službi, u zavisnosti od odabranog modela. Značajan segment predstavlja i informaciono - komunikaciona i telekomunikaciona oprema koja bi se koristila u budućim centrima 112, kao i softverska rešenja koja bi bila u upotrebi. Ipak, koristi od potpune implementacije i upotrebe broja 112 bi bili značajni pa se očekuje nastavak i finalizacija ovog procesa.

\section{LITERATURA}

[1] Savet Evropske unije (1991). Odluka Saveta Evrope o uvođenju jedinstvenog evropskog broja za hitne službe 112, Brisel, Belgija

[2] “Sl. glasnik RS”, br. 111/2009, 92/2011 i 93/2012. Zakon o vanrednim situacijama Preuzeto Mart 10, 2017, sa https://www.paragraf.rs/propisi/zakon_o_ vanrednim_sitsituacij.html

[3] EENA Operations Document. (2011) 112 Service Chain Description.

[4] Vratonjić, M. (2012). Služba 112 - unapređeni sveobuhvatni odgovor $u$ hitnim i kritičnim situacijama. Telekomunikacije - Stručno - naučni časopis Republičke agencije za elektronske komunikacije. Beograd

[5] Ministarstvo unutrašnjih poslova Republike Srbije (2012). Nacrt izveštaja Ministarstva unutrašnjih poslova Republike Srbije o Službi 112. MUP RS. Beograd

[6] Milenković, M., Kekić, D., Glavaš, D. (2017). Grad Beograd kao primer dobre prakse u upotrebi modernih infomaciono - komunikacionih tehnologija u komunikaciji između građana $i$ gradske vlasti. Fourth International Scientific Conference Sinteza 2017. Beograd. 